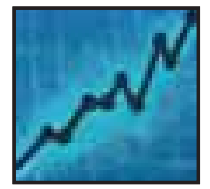

\title{
Quarterly Index
}

\section{AGING AND PLANNING FORTHE FUTURE}

As the size of the older population increases, matters pertaining to advanced care planning, home care and palliative care become more important to hospitals and other healthcare providers.

\section{Advanced Care Planning Undertaken by Minority}

Advanced care planning is an area of concern to hospitals because of issues relating to DNR (do not resuscitate) orders and medical care in cases of incompetence.

Only one-third of older children (35-55 years of age) report that their parents have expressed their wishes about care in the event they become unable to care for themselves.

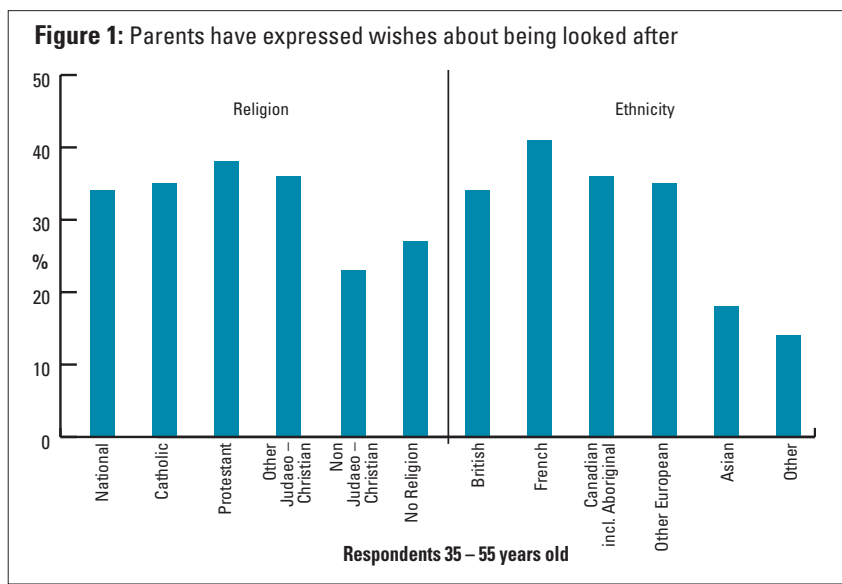

Of particular note are the important differences by religion and ethnicity. Protestant and Catholic adult children are most likely to report that their parents have made their wishes known; however, among non-religious adult children or those of non-Judaeo-Christian background, only about one-quarter report their parents have made plans. Among those who report they are of Asian or "other" ethnicity, fewer than one in five report their parents have made plans.

Among those who report their parents have expressed wishes about medical care in the event of incompetence, fewer than half report that these wishes have been expressed in writing. Here again, ethnicity appears to play a major role. (See Figure 2)

People of "other" ethnicity are the least likely to report that their parents have made plans, but the most likely to report that the plans are in writing. Asians, also among the least likely to report their parents have expressed their wishes, are the most likely to report that these wishes have been expressed verbally.

One conclusion is that persons of different ethnic backgrounds and religions approach advanced family care planning with differing values and customs. From the

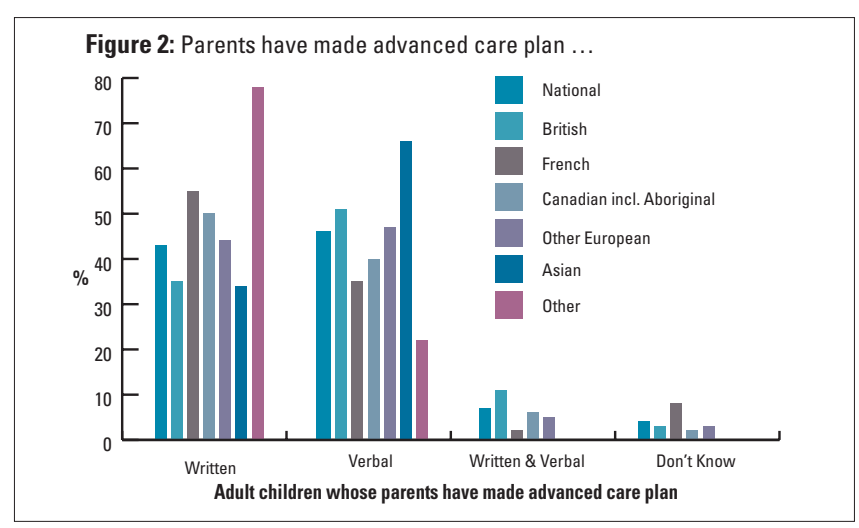

perspective of the hospital and healthcare provider, these differences present significant challenges.

Among contemporary seniors, however, the numbers are not much higher. Slightly more than half report they are aware that the law allows them to plan for their future care and appoint someone to carry out the decisions.

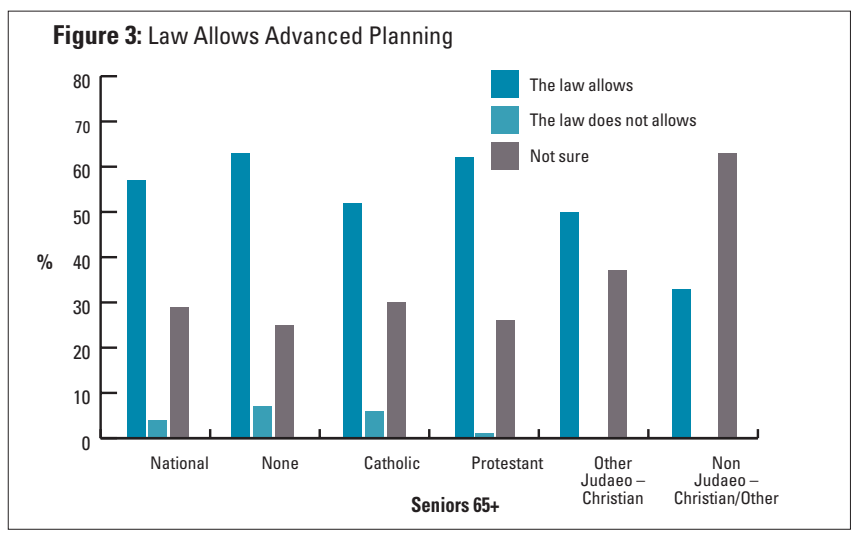

Here again, we find significant differences by religion. People of non-Judaeo-Christian religions are most likely not to know about the law. The ethnic data reveal a similar pattern. Read this data with an awareness that respondents are those seniors conversant in English or French. Judging by these data, seniors not able to participate in the questionnaire because of language (e.g., new immigrants) are unlikely to have made advanced care plans or to be aware of the legislation enabling them to do so.

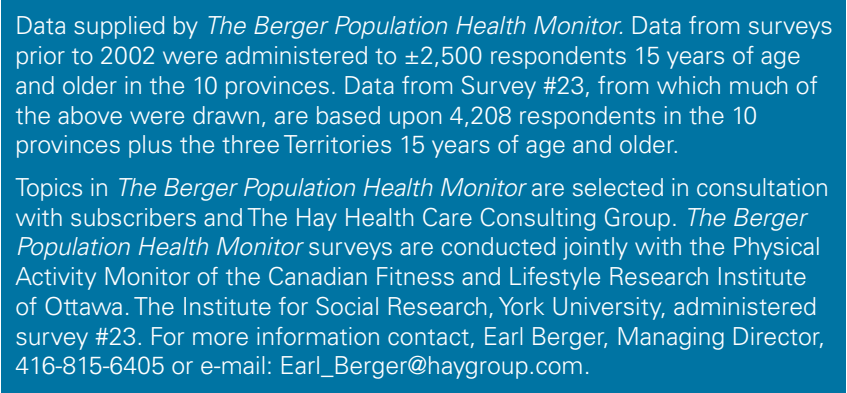
prior to 2002 were administered to $\pm 2,500$ respondents 15 years of age and older in the 10 provinces. Data from Survey \#23, from which much of the above were drawn, are based upon 4,208 respondents in the 10 provinces plus the three Territories 15 years of age and older.

Topics in The Berger Population Health Monitor are selected in consultation with subscribers and The Hay Health Care Consulting Group. The Berger Population Health Monitor surveys are conducted jointly with the Physical Activity Monitor of the Canadian Fitness and Lifestyle Research Institute of Ottawa. The Institute for Social Research, York University, administered 416-815-6405 or e-mail: Earl_Berger@haygroup.com. 